\title{
Puolikorkeiden pensasmustikoiden radikaalien leikkaustapojen vaikutus pensaan kasvuun sekä talvehtimiseen
}

Kirsi Salminen, MTT, Latokartanonkaari 9,00790 Helsinki,etunimi.sukunimi@mtt.fi

\section{Tiivistelmä}

Pensasmustikka on kaupallisesti merkittävä marja maailmalla. Suomessakin kiinnostus pensasmustikkaa kohtaan on kasvussa. Vuonna 2011 viljelijöiden lukumäärä oli 162, satoikäisen kasvuston pinta-ala 69 ha ja satomäärä 128 tonnia.

Suomessa viljelyn ongelmana on talvenkestävien lajikkeiden rajallinen määrä. Pensasmustikan sadonkorjuu sekä pensaiden leikkuu vaativat osaavaa ja sitoutunutta työvoimaa. Ammattitaitoisen työvoiman saatavuus ja tuotantokustannusten pitäminen kohtuullisella tasolla ovat haaste viljelijöille.

Perinteisessä pensasmustikan leikkuussa vaurioituneet ja sairaat versot tai niiden osat, maahan taipuvat sekä toisiaan vasten hankaavat versot poistetaan. Vanhoja pensaita nuorennetaan poistamalla vanhimpia versoja. Tapa on hidas ja kallis. Hämeen Ammattikorkeakoulun Puutarhatalouden koulutusohjelmassa tehdyn opinnäytetyön tavoitteena oli selvittää onko puolikorkean pensasmustikan perinteiselle leikkaustavalle vaihtoehtoa. Työn kokeellinen osuus suoritettiin hämäläisellä pensasmustikkaviljelmällä case-tutkimuksena.

Kokeessa käytettiin kahta perinteistä radikaalimpaa, raivaussahalla toteutettua leikkaustapaa: pensaan leikkaus kokonaan ja puoliksi alas. Verrokkina oli perinteinen leikkaus. Lajikkeina olivat kotimaiset Aino ja Alvar. Pensaat olivat kokeen alkaessa 11 vuotiaita. Työssä tutkittiin leikkaustapojen vaikutusta pensaiden talvenkestävyyteen ja kasvuun sekä lajikkeiden välisiä eroja. Leikkaukset tehtiin toukokuussa 2012 ja viimeiset mittaukset toukokuussa 2013.

Voimakkailla leikkaustavoilla pensaiden uusien versojen vegetatiivinen kasvu oli runsasta. Lajikkeiden välillä merkittäviä eroja ei havaittu. Talvivaurioiden määrässä lajikkeiden välisiä eroja havaittiin. Aino -lajikkeella kaikilla leikkaustavoilla esiintyi vähäisiä pakkasvaurioita versojen kärkiosassa. Alvar -lajikkeella oli erittäin pahoja talvivaurioita: Kaikissa perinteisesti leikatuissa pensaissa yli $75 \%$ pensaan versoista oli vaurioitunut. Puoliksi alas leikatuissa pensaissa vaurioiden määrä oli hieman pienempi. Kokonaan alas leikatuissa Alvar-pensaissa talvivaurioiden määrä oli huomattavasti vähäisempi, niissä kaikissa vaurioita oli korkeintaan puolessa versoista. Mikään koealueen pensaista ei kuollut kokonaan.

Tulos tukee viljelijöiden havaintoa, että Alvar on alttiimpi talvivaurioille kuin Aino, vaikka kumpaakin suositellaan I-IV kasvuvyöhykkeelle. Tulokseen vaikutti talven 2012-2013 olosuhteet: talvi oli keskimääräistä lumisempi ja maaliskuu 2013 oli harvinaisen kylmä ja aurinkoinen. Tutkimus vaatisikin jatkoa, jotta voitaisiin arvioida eri leikkaustapojen vaikutusta sadontuottokykyyn, pensaiden kasvuun pidemmällä aikavälillä sekä sääoloiltaan erilaisten talvien vaikutusta pensaiden talvehtimiseen. Lisäksi tulisi löytää keino, jolla voimakkaasti leikattujen pensaiden versojen runsasta vegetatiivista kasvua voitaisiin hallita.

\section{Asiasanat}

pensasmustikka, leikkaus, talvenkestävyys, Vaccinium Angustifolium -ryhmä 


\section{Johdanto}

Pensasmustikoiden tuotanto ja kauppa on merkittävää maailmanlaajuisesti. Agricultural Marketing Resource Center pitää sitä USA:n kaupallisesti toiseksi tärkeimpänä marjana. USA:ssa pensasmustikkaa onkin jalostettu ja viljelty 1900-luvun alusta lähtien. Suomessa viljelyn ongelmana on ollut talvistamme selviävien lajikkeiden puute. Tällä vuosituhannella pensasmustikan viljely on päässyt kuitenkin vauhtiin myös meillä. Kuluttajien kiinnostus marjaa kohtaan näyttäisi olevan tulevaisuudessa kasvamassa niin Suomessa kuin maailmanlaajuisesti. Tämä ei ole ihme, sillä pensasmustikan marjan maku on mieto ja makeahko, se ei sotke, sen poiminta on vaivattomampaa kuin metsämustikoiden poiminta ja sen rakenne kestää hyvin erilaisia käsittelyjä. Pensasmustikka sopii hyvin sekä tuorekäyttöön että säilöntään.

Hämeen Ammattikorkeakoulussa puutarhatalouden koulutusohjelmassa tehdyn opinnäytetyön tavoitteena oli selvittää onko perinteiselle puolikorkean pensasmustikan leikkaustavalle olemassa vaihtoehtoa. Kokeellisessa osuudessa selvitettiin yhden vuoden ajalta kahden raivaussahalla toteutetun voimakkaan leikkaustavan (pensaiden kokonaan ja puoliksi alas leikkaus), soveltuvuutta Suomessa viljeltäville pensasmustikkalajikkeille: Tutkimuksessa selvitettiin miten leikkaukset vaikuttavat pensaiden talvehtimiseen ja kasvuun. Työn tilaajana oli Iso-Hiiden Kartano Oy Janakkalasta. Tilaajalla oli tarvetta ja kiinnostusta selvittää pensasmustikan leikkuuseen taloudellisempia ja vähemmän työvoimaa vaativia vaihtoehtoja. Leikkaustapa ei saa kuitenkaan vähentää tuottavuutta pitkällä tähtäimellä.

\section{Aineisto ja menetelmät}

Koe tehtiin Janakkalassa työn tilaajan mustikkaviljelmällä. Koe aloitettiin pensaiden leikkauksilla toukokuussa 2012. Pensaita tarkkailtiin toukokuuhun 2013 asti, jolloin lopulliset mittaukset tehtiin. Tutkimuksessa oli mukana 90 pensasta. Lajikkeina oli kaksi puolikorkeaa kotimaista lajiketta 'Aino' ja 'Alvar'. Ristipölytyksen varmistamiseksi niitä viljellään perinteisesti rinnakkain.

Tutkimuksessa laskettiin leikattuihin pensaisiin kasvaneiden uusien versojen määrää $(\mathrm{kpl})$ ja mitattiin kolmen pisimmän uuden verson pituus $(\mathrm{cm})$. Tuloksista laskettiin keskiarvot. Lisäksi arvioitiin silmämääräisesti kaikista koealueen pensaista kukinnan ja kukkanuppujen määrää suhteessa eläviin oksiin asteikolla:

- $\quad 0=$ ei kukkia

- $\quad 1=$ muutama kukka

- $\quad 2=$ keskinkertainen kukinta

- $\quad 3=$ runsas kukinta.

$-$

Talvivaurioiden määrää arvioitiin asteikolla:

- $0=$ kuollut

- $1=$ =rittäin pahoja talvivaurioita

- $\quad 2=$ pahoja talvivaurioita (n.75\% versoista kuollut tai vaurioitunut)

- $\quad 3=$ vaurioita (n.50\% versoista vaurioitunut)

- 4=lieviä vaurioita (versojen kärkiosia vaurioitunut, $\max 25 \%$ )

- $\quad 5=$ =ei vaurioita (pienet/yksittäiset vauriot sallittuja). 


\section{Tulokset ja niiden tarkastelu}

Pensaiden vegetatiivista kasvua tutkittiin kahdella mittarilla:

1) Laskettiin pensaisiin kasvaneet uudet versot $(\mathrm{kpl})$.

2) Mitattiin kustakin pensaasta kolme pisintä uutta versoa ja laskettiin niistä keskimääräinen pituus $(\mathrm{cm})$.

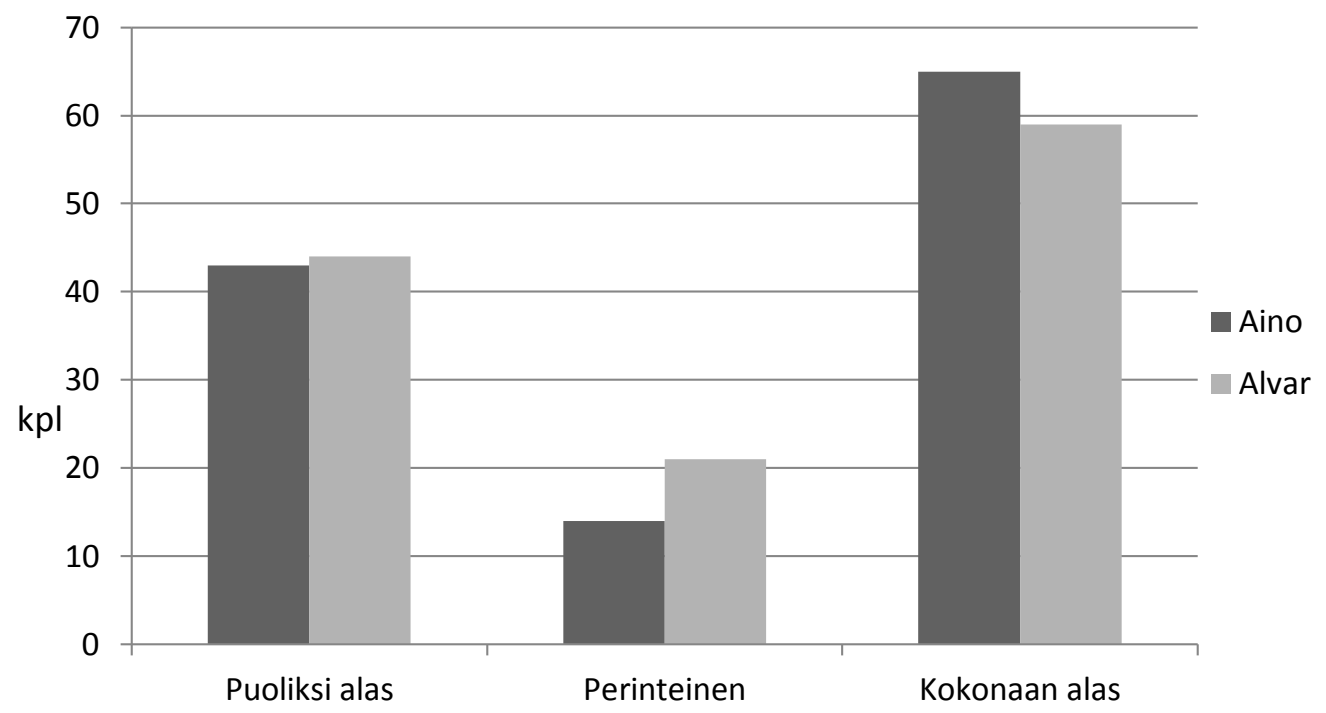

Kuvio 1. Pensasmustikan uusien versojen määrä ( $\quad$ kpl) pensaissa keskimäärin.

Pensaan uusien versojen kappalemäärä oli riippuvainen paitsi leikkaustavasta myös pensaan koosta. Uusia versoja kasvoi perinteisellä leikkaustavalla odotetusti vähiten ja kokonaan alas leikattaessa eniten (Kuvio 1). Perinteisesti leikatuissa Aino-pensaissa oli vähimmillään 7 uutta versoa ja enimmillään 25 uutta versoa. Kokonaan alas leikatuissa Aino-pensaissa oli vähimmillään 43 uutta versoa ja enimmillään 84 uutta versoa. Versojen alas leikkauksen seurauksena apikaalidominanssi purkautui ja versojen tyvellä olleet lepotilaiset silmut lähtivät kasvuun. Voimakkaasti leikatuissa pensaissa syntyi voimakasta versojen vegetatiivista kasvua.

Kokonaan alas leikattuihin 'Ainoihin' uusia versoja kasvoi keskimäärin hieman enemmän kuin 'Alvariin'. Molempia lajikkeita kuvaillaan reheväkasvuisiksi ja runsasversoisiksi. Perinteisessä leikkaustavassa Alvar-lajikkeeseen uusia versoja kasvoi tässä tutkimuksessa kuitenkin keskimäärin puolitoistakertainen määrä 'Ainoon' verrattuna. Tämä johtuu siitä, että 'Alvaria' jouduttiin runsaampien talvivaurioiden vuoksi leikkaamaan perinteisellä leikkaustavalla enemmän kuin 'Ainoa'. Voimakkaat leikkaukset aiheuttivat pensaissa voimakkaampaa vegetatiivista kasvua. 


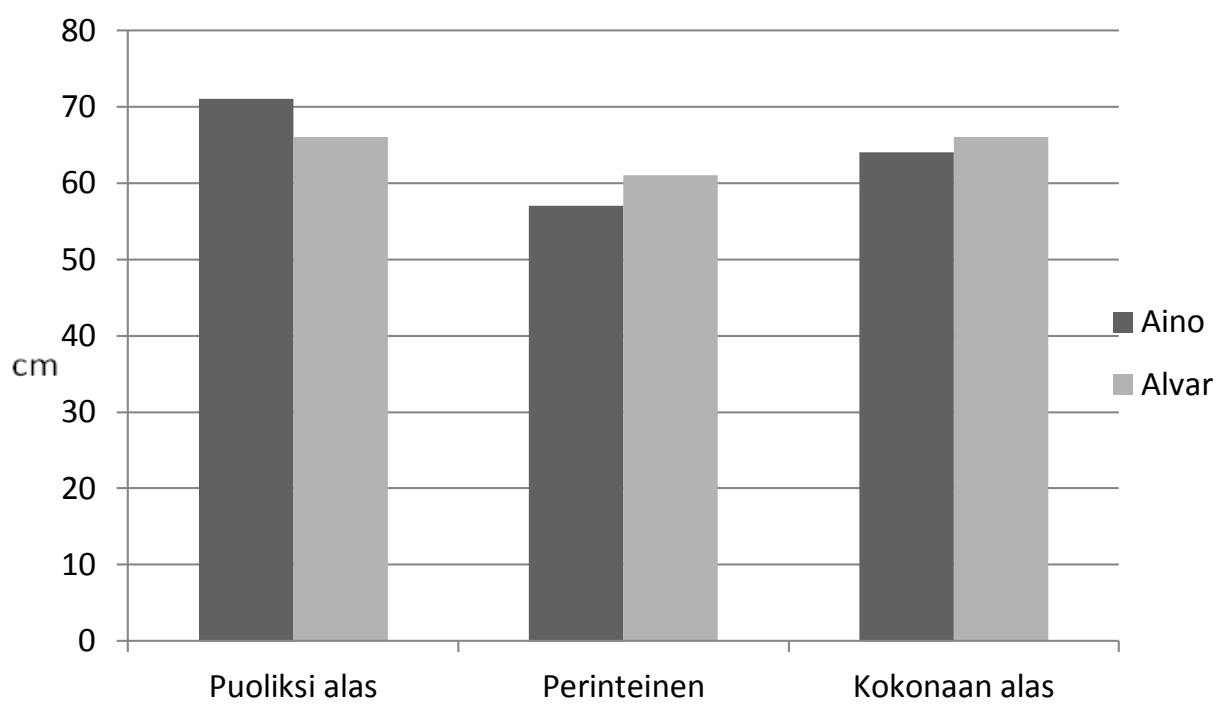

Kuvio 2. Pensasmustikkapensaan kolmen pisimmän uuden verson keskipituus (cm).

Perinteisellä leikkaustavalla leikattaessa versojen pituus jäi keskimäärin hieman lyhyemmäksi kuin voimakkailla leikkaustavoilla (Kuvio 2). Perinteisesti leikatuissa Aino-pensaissa versojen keskipituuden keskihajonta oli 9,8 cm, puoliksi alas leikatuissa pensaissa $9,2 \mathrm{~cm}$ ja kokonaan alas leikatuissa pensaissa vain $5,5 \mathrm{~cm}$. Voimakkaampi vegetatiivinen kasvu näkyy lievästi siis myös uusien versojen pituudessa. Lajikkeiden välistä eroa versojen pituudessa ei ilmennyt.

Pensaiden kukintaa arvioitiin silmämääräisesti asteikolla 0-3 toukokuussa 2013. Jos pensaassa oli yksikin kukka tai kukkanuppu, rekisteröitiin se ykkösenä. Kukkien ja kukkanuppujen määrä suhteutettiin pensaan elävien versojen määrään. Uudet, vuoden vanhat, versot eivät yleensä kuki. Osassa voimakkaasti leikatuista pensaista havaittiin kuitenkin yksittäisiä kukkia ja kukkanuppuja molemmilla lajikkeilla (Kuvio 3).

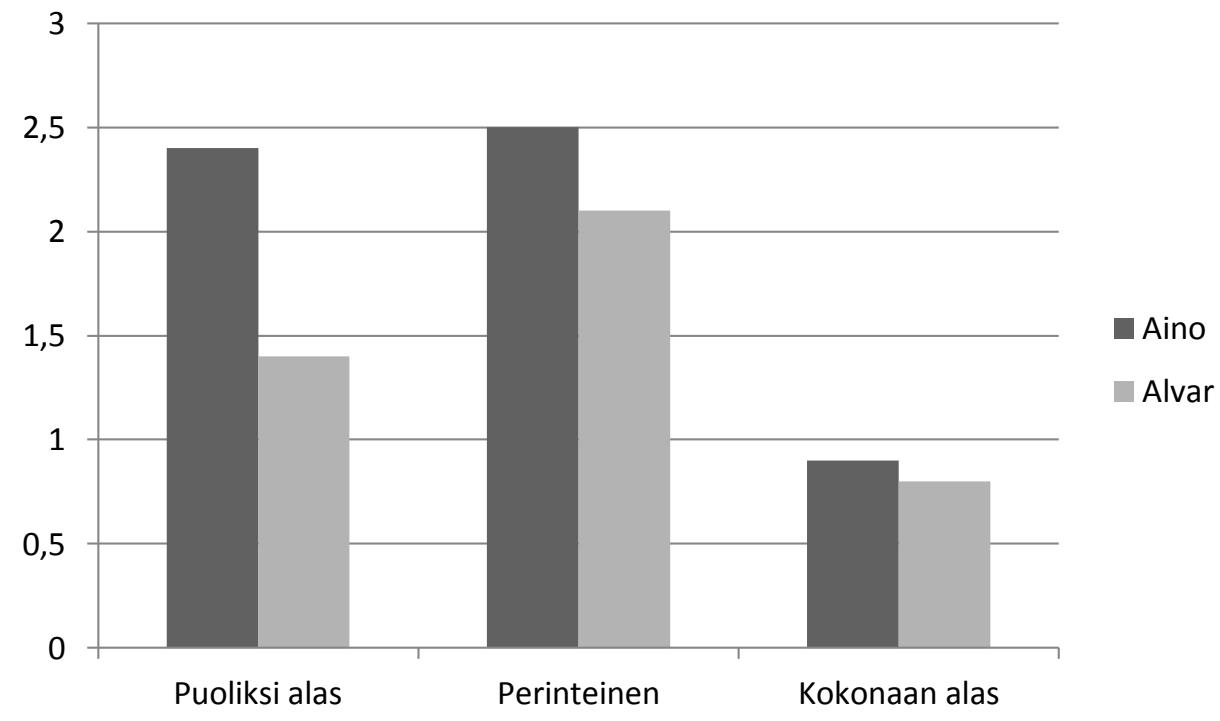

Kuvio 3. Pensaiden kukinta arvioituna asteikolla $0-3$. 
Lajikkeita vertaillessa 'Alvarin' kukinta ja kukkanuppujen määrä oli kaikissa leikkaustavoissa pienempi kuin 'Ainossa' (Kuvio 3). 'Ainossa' ei havaittu eroa kukinnan määrässä puoliksi alas leikattujen ja perinteisesti leikattujen pensaiden välillä. 'Alvarin' vähäisempi kukinta perinteissä tavassa johtuu osittain suuremmasta nuorien versojen määrästä: Pensaita jouduttiin leikkaamaan voimakkaammin kuin 'Ainoja' runsaista talvivaurioista johtuen.

Pensaiden talvivaurioiden määrää arvioitiin asteikolla 0-5 toukokuussa 2013 (Kuvio 4). Talvivaurioiden määrässä havaittiin lajikkeiden välillä selvä ero.

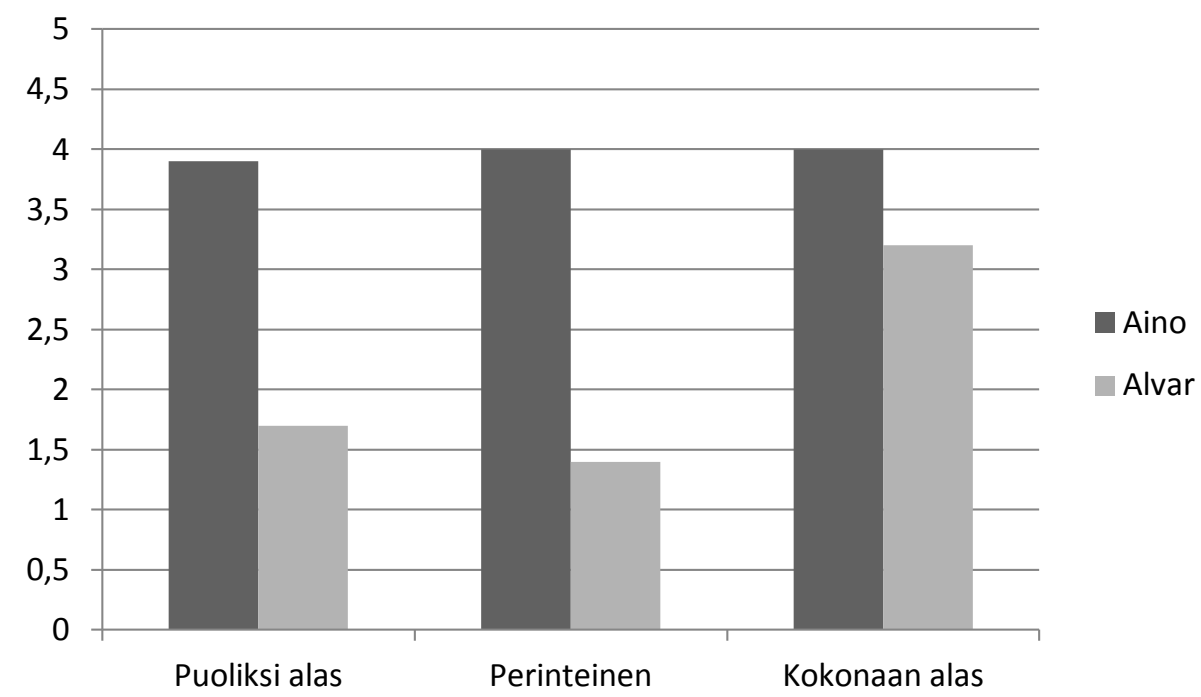

Kuvio 4. Pensasmustikoiden talvivaurioiden määrä arvioitu asteikolla 0-5.

Aino-lajikkeella oli tasaisesti vähäisiä pakkasvaurioita versojen kärkiosassa kaikilla leikkaustavoilla (Kuva 1). Alvar-lajikkeella oli erittäin pahoja talvivaurioita lähes kaikissa perinteisesti ja puoliksi alas leikatuissa pensaissa. Jopa $75 \%$ versoista oli kuollut. Kokonaan alas leikatuissa Alvar-pensaissa talvivaurioiden määrä oli lähempänä Aino-pensaiden tasoa. Mikään koealueen pensaista ei ollut kuitenkaan kokonaan kuollut.

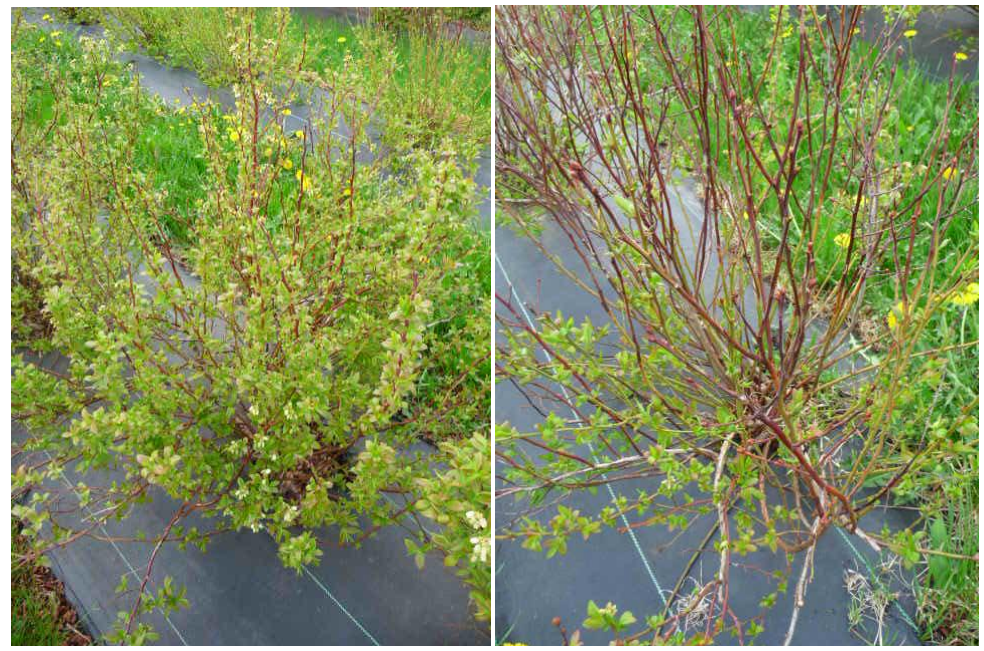

Kuva 1. Hyvin talvesta selvinnyt 'Aino' ja pahoja talvivaurioita kärsinyt 'Alvar' toukokuussa 2013. 
Pensaiden talvehtimiseen vaikutti talven 2012-2013 olosuhteet: leuto syksy vaihtui nopeasti ankaraksi pakkasjaksoksi. Talvi oli keskimääräistä lumisempi ja maaliskuu 2013 oli puolestaan harvinaisen kylmä ja aurinkoinen. 'Alvarin' pidemmälle kehittyneet silmut olivat lepotilan purkautuessa alttiimpana voimakkaiden lämpötilanvaihteluiden aiheuttamille vaurioille. Paksu lumipeite suojasi puolestaan nuoria versoja. Mikäli talvi olisi ollut vähäluminen, olisi tulos kokonaan alas leikattujen pensaiden kohdalla ollut varmasti aivan toisenlainen.

\section{Johtopäätökset}

Opinnäytetyön tarkoituksena oli selvittää erilaisten leikkaustapojen vaikutuksia pensasmustikan kasvuun ja talvehtimiseen. Tutkituissa voimakkaasti leikatuissa pensaissa versojen vegetatiivinen kasvu oli runsasta. Lajikkeiden välillä ei havaittu merkittäviä eroja. Talvenkestävyydessä eroja lajikkeiden välillä sen sijaan havaittiin. 'Alvari' oli 'Ainoa' arempi talvivauriolle kaikilla leikkaustavoilla. Talvehtimisen onnistumista arvioitaessa tämän kokeen tulokseen vaikutti talven 2012-2013 olosuhteet. Tutkimuksen tulos tukee kuitenkin viljelijöiden havaintoa, että 'Alvar' on alttiimpi talvivaurioille kuin 'Aino', vaikka kumpaakin on aikaisemmin suositeltu I-IV kasvuvyöhykkeelle.

Jotta voitaisiin arvioida pidemmällä aikavälillä voimakkaiden leikkaustapojen vaikutusta puolikorkeiden pensasmustikoiden talvehtimiseen, kasvuun ja sadontuottokykyyn, tulisi koetta jatkaa. Paras mittari eri leikkaustapojen vaikutuksesta pensaan kasvuun olisi pensaiden tuottama sato; sen määrä ja laatu. Tutkimuksessa käytetyt kasvun mittarit kertoivat vain pensaiden vegetatiivisesta kasvusta.

Työskentely raivaussahalla on huomattavasti nopeampaa kuin perinteisellä leikkaustavalla. Käyttämällä raivaussahaa leikkaustyössä saataisiin aikaan merkittäviä säästöjä työajassa. Voimakkaat leikkaukset lisäävät versojen vegetatiivista kasvua ja tutkitut pensaat kasvattivatkin todella runsaasti uusia versoja. Jos suurelle versomäärälle ei tehdä mitään, vaikutukset pensaan sadontuottoon alkavat näkyä ennen pitkään. Tulisikin löytää jokin vähän työaikaa vievä työskentelytapa, jolla pensaita jatkossa käsitellään, jotta raivaussahalla saatua hyötyä ei menetetä.

Tämän tutkimuksen perusteella puolikorkean pensasmustikan viljelijällä ei ole vaihtoehtoa perinteiselle leikkaustavalle. Tulokset voimakkaiden leikkaustapojen vaikutuksista pensaan kasvuun aiheuttavat enemmän uusia kysymyksiä kuin antavat vastauksia. Leikkaaminen on välttämätön hoitotoimenpide pitkäikäiselle ja pitkään satoa tuottavalle pensasmustikalle. Leikkaukset takaavat pensaiden tuottavan kasvun vuosikymmeniksi. Säännöllisesti tehdyt leikkaukset jakavat kustannukset tasaisesti pensaan koko elinkaaren ajalle. Uusia leikkaus- ja työskentelytapoja tulisi kuitenkin kehittää, jotta pensasmustikan viljely olisi Suomessa taloudellisesti kannattavaa ja pensasmustikka saisi ansaitsemansa aseman kotimaisten marjojen joukossa. 


\section{Kirjallisuus}

Albert, T., Karp, K., Starast, M. \& Paal, T. 2010. The effect of mulching and pruning on the vegetative growth and yield of the half-high blueberry. Teoksessa Agronomy Research 8. 759-769.

Agronomic Factors Affecting Blueberry Fruit Quality in Northern Highbush Blueberries n.d. Department of Environment And Primary Industries State Government of Victoria. Viitattu 14.8.2013

http://www.dpi.vic.gov.au/agriculture/horticulture/fruit-nuts/berries/ag1422-agronomic-factors-affecting-blueberryfruit-quality-in-northern-highbush-blueberries

Eck, P. \& Childers, N.F. 1989.The blueberry industry. Teoksessa Eck, P. \& Childers, N.F. (toim.) Blueberry culture. London: Rutgers University Press, 3-13.

Ferree, D.C. \& Scupp, J.R. 2003. Pruning and training physiology. Teoksessa Ferree, D.C. \& Warrigton, I.J. (toim.) Apples Botany, Prodution and Uses. CAB International, 319-344.

Gough, R.E. 1994. The highbush blueberry and its management. Food Products Press An Imprint of The Haworth Press Inc.

Havas, P. \& Sulkava, S.1987. Suomen luonnon talvi. Helsinki: Kirjayhtymä Oy

Heidenreich, C. Blueberry pruning brush-up-no pun intended. Department of Horticulture, Cornell University's College of Agriculture and Life Sciences, Ithaca, NY 14853. Viitattu 26.1.2013

http://www.fruit.cornell.edu/berry/production/pdfs/blueberries/blueberrypruningbrushup.pdf

Lehmushovi, A., Ylämäki, A. \& Tahvonen, R. 1999. Pensasmustikan hoito-ohjeista. Piikkiö: MTT puutarhatuotanto

Paasisalo, S., Kokko, H. \& Kärenlampi, S. 1994. Pensasmustikka marjantuotannossa: kasvatus- ja hoito-ohjeita. Kuopio: Liikekirjanpaino Ky 